\title{
APLIKASI DESAIN BIOFILIK DALAM KOMUNITAS SENIOR DI JAKARTA UTARA
}

\author{
Nathania Jifia ${ }^{1)}$, Mieke Choandi $^{21}$ \\ 1)Program Studi S1 Arsitektur, Fakultas Teknik, Universitas Tarumanagara, nathaniajifia@gmail.com \\ 2) Program Studi S1 Arsitektur, Fakultas Teknik, Universitas Tarumanagara, miekec@ft.untar.ac.id
}

Masuk: 04-07-2021, revisi: 14-08-2021, diterima untuk diterbitkan: 23-10-2021

\begin{abstract}
Abstrak
Tingkat harapan hidup yang terus meningkat mengakibatkan populasi lansia di seluruh dunia semakin bertambah. Menurut data BPS, diperkirakan pada tahun 2035 jumlah lansia di Indonesia akan mencapai 48,2 juta jiwa atau sekitar 15,8\% dari seluruh penduduk Indonesia. Meningkatnya populasi lansia menyebabkan peningkatan ketergantungan lansia yang diakibatkan oleh proses penuaan. Di jaman yang lebih modern ini, lansia membutuhkan keseharian agar merasa berguna. Solusi desain yang dimunculkan adalah sebuah komunitas yang menyediakan fasilitas untuk mendukung aktivitas lansia. Tujuannya agar lansia tetap aktif dan produktif di usia yang menuntut pergerakan yang terbatas, agar dapat merubah pandangan masyarakat bahwa lansia adalah beban. Lokasi di Jakarta utara dipilih dengan mempertimbangkan variabel ekonomi dan kepadatan penduduk untuk menentukan target pengguna yaitu menengah keatas. Kategori pengguna proyek adalah komunitas independent living, yaitu orang dewasa yang lebih tua berusia 55 tahun ke atas. Menurut WHO, salah satu faktor yang mempengaruhi kualitas hidup manusia dalam proses penuaan adalah lingkungan fisik. Desain bangunan dapat berperan dalam meningkatkan kesehatan dan kesejahteraan hidup lansia. Konsep desain biofilik diaplikasikan dalam proyek dengan dasar kajian dari 14 patterns of biophilic (Terrapin, 2014) dan the practice of biophilic design (Kellert, 2015), yang diwujudkan pada tapak dan massa bangunan.
\end{abstract}

Kata kunci: Biofilik; Komunitas Lansia; Penuaan; Kualitas hidup

\begin{abstract}
The increasing life expectancy resulted in expanding numbers of elderly worldwide. According to BPS data, by 2035, the number of elderly in Indonesia will reach 48.2 million people or about $15.8 \%$ of the entire population of Indonesia. The increasing population leads to escalated dependence of the elderly caused by the aging process. In this modern era, the elderly need daily activities to feel useful. The solution that emerged is a community that provides facilities for the elderly. The goal is for elderly remains active and productive at the age that demands limited movement. North Jakarta was chosen as location by considering economic variables and population density to determine the target user, namely the midupper class. The user category are the independent living community, the older adults aged 55 and over. According to WHO, one factor that affects the quality of human life include the ageing is the physical environment. Building design can play a role in improving the health and welfare of the elderly. The concept of biophilic design applied in the project, based on the study of 14 patterns of biophilic (Terrapin, 2014) and the practice of biophilic design (Kellert, 2015), which applied in the site and building mass.
\end{abstract}

Keywords: ; Ageing ; Biofilic Design ; Senior Community,; Quality of life

\section{PENDAHULUAN}

\section{Latar Belakang}

Harapan hidup yang terus meningkat, menyebabkan laju penuaan populasi di banyak negara berkembang saat ini secara substansial lebih cepat terjadi dari yang terjadi di negara maju pada masa lalu. Akibatnya, populasi lansia tumbuh lebih cepat daripada anak-anak. Dari data BPS, pada tahun 2035 jumlah penduduk lansia di Indonesia akan mencapai 48,2 juta penduduk atau sekitar 15,8\% dari 
jumlah penduduk. Di Jakarta sendiri, jumlah lansia menurut Badan Pusat Statistik mencapai 869.684 jiwa pada tahun 2018.
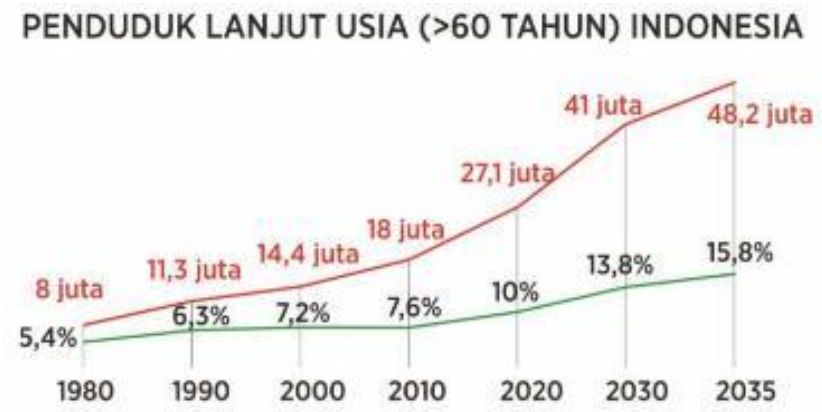

Gambar 1. Grafik Pertumbuhan Penduduk Lanjut Usia di Indonesia

Sumber: Sensus Penduduk, 2019

Meningkatnya populasi lansia menyebabkan peningkatan ketergantungan lansia yang diakibatkan oleh proses penuaan. Permasalahan pada lansia terjadi karena kondisinya yang semakin menurun antara lain; kondisi mental, keterasingan, penyakit, dkk. Dengan keterbatasan yang dialami maka harus diciptakan suatu lingkungan yang dapat membantu aktivitas lansia dengan keterbatasannya.

Proses menua merupakan suatu perubahan yang ditimbulkan oleh kemunduran fisik dan psikis, yang akhirnya akan berdampak pada sosial dan ekonomi serta pada aktivitas kehidupan sehari-hari (Fatimah, 2010). Menurut BKKPN Surya Chandra Surapaty, Kondisi sosial di Indonesia belum siap menerima lansia sebagai golongan produktif sehingga tidak perusahaan yang menerima lansia untuk bekerja. Lansia membutuhkan sarana untuk tetap aktif dan produktif di usia yang menuntut pergerakan yang terbatas, agar dapat mengubah pandangan masyarakat bahwa lansia adalah beban.

Lansia memerlukan keseharian agar merasa berguna, terutama untuk dirinya sendiri. Hal ini dapat diwujudkan dengan menyediakan suatu komunitas yang menyediakan fasilitas yang mendukung aktivitas lansia. Pemenuhan kebutuhan sosial lansia di komunitas cenderung lebih baik dari pada di panti, karena interaksi di komunitas pada dasarnya lebih luas dari pada antar lansia di panti werdha. Lansia yang ditempatkan di dalam panti cenderung merasa dititipkan dan merasa kurang nyaman. Sedangkan di komunitas, lansia dapat beraktivitas dan bersosialisasi lebih baik dengan sesama lansia.

Di Jakarta, wadah penyediaan komunitas lansia masih sangat minim. Pada usia lanjut, seseorang tidak hanya harus menjaga kesehatan fisik tetapi juga kondisi mentalnya agar dapat menghadapi perubahan yang mereka alami. Salah satu faktor yang mempengaruhi kualitas hidup manusia adalah lingkungan tempat tinggalnya. Pola desain bangunan harus dapat berperan dalam meningkatkan kesehatan dan kesejahteraan hidup lansia.

Manusia memiliki kecenderungan bawaan untuk berhubungan dengan alam. Desain Biophilik adalah suatu konsep desain yang memiliki tujuan untuk menghasilkan suatu ruang yang dapat berpartisipasi dalam peningkatan kesejahteraan hidup manusia secara fisik dan mental dengan membina hubungan antara manusia dan alam. Menurut buku 14 patterns of biophilic, terdapat tiga kategori pendekatan biofilik yang dapat diaplikasikan ke dalam bangunan untuk meningkatkan kualitas bangunan dan manusia di dalamnya.

\section{Rumusan Permasalahan}

Masalah yang dapat dirumuskan adalah bagaimana peran arsitektur dalam mewadahi pertumbuhan populasi lansia serta eksistensinya di masa depan, sehingga lansia dapat hidup dengan mandiri di lingkungan komunitasnya. Program yang diajukan harus dapat menjawab tantangan melampaui ekologi, baik dari segi ekologi manusia maupun ekologi bangunan. 


\section{Tujuan}

Proyek bertujuan untuk menyediakan pelayanan sosial dan komunitas khususnya bagi lansia di perkotaan, dengan menghadirkan suasana yang menyenangkan sehingga kualitas kehidupan lansia lebih baik. Pendekatan desain biofilik diaplikasikan ke dalam tapak dan massa bangunan untuk mendukung interaksi lansia dengan alam. Dengan menerapkan ide konsep biofilik dalam perancangan ada beberapa hal positif yang bisa didapat, antara lain meningkatkan kenyamanan, menstabilkan tekanan darah, dan mencegah depresi. Proyek ini dapat menjadi destinasi baru di Jakarta Utara sehingga lansia yang ingin bersosialisasi dan menemukan jati dirinya.

\section{KAJIAN LITERATUR}

\section{Manusia Lansia}

Usia lanjut dikatakan sebagai tahap akhir perkembangan pada daur kehidupan manusia. Menurut WHO (world health organization), usia lanjut dibagi menjadi empat kriteria yaitu tahap lanjut dari suatu proses 45-59 tahun; lanjut usia (elderly) ialah 60-74 tahun, lanjut usia tua (old) ialah 75-90 tahun, usia sangat tua (very old) ialah di atas 90 tahun. Cooper dan Francis (1998) mengelompokkan lansia menjadi tiga bagian berdasarkan usia dan tingkat keaktifannya, dengan penjelasan sebagai berikut:

Tabel 1. Pengelompokan Lansia

\begin{tabular}{|c|c|c|c|}
\hline & Young Old & Old & Old-old \\
\hline Usin & Antara Usia 55-70 tahun & Antara usia $70-50$ tahun & 80 tahun ke atas \\
\hline Kemampuan & $\begin{array}{l}\text { Mandin dalam bergerak, } \\
\text { alikit }\end{array}$ & $\begin{array}{l}\text { Cukup mandiri dalam } \\
\text { bergerak, semi aktif }\end{array}$ & $\begin{array}{l}\text { Kurang mandiri, memiliki } \\
\text { keterbatasan gerok dan } \\
\text { membutuhkan perawatan } \\
\text { lebih, pasif }\end{array}$ \\
\hline Aktivitas & $\begin{array}{l}\text { Inisiatif sendiri, santal, } \\
\text { rekreasi, bersosialisasi, } \\
\text { berhubungan dengan } \\
\text { kesehatan }\end{array}$ & \begin{tabular}{|l|} 
Inisisatif sendiri dan \\
belompok, mulal jarang \\
berpindah (duduk terusi, \\
bersosialsasl, berhubung: \\
an dengan kesehatan
\end{tabular} & 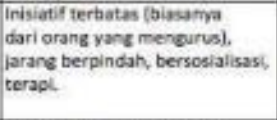 \\
\hline Kandivi Umum & 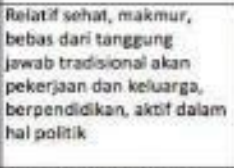 & $\begin{array}{l}\text { Membutuhkan pelayanan } \\
\text { sosial yang mendukung. } \\
\text { fitur-fitur spesial pada } \\
\text { Ingkungan fisik seiring } \\
\text { dengan masalah-masalah } \\
\text { kesehatan yarg berkembane } \\
\text { pada divi mereka }\end{array}$ & $\begin{array}{l}\text { Membutukikan peiaryanan } \\
\text { sosial yane mendukune } \\
\text { fitur-titur spesial pada } \\
\text { lingkungan fisk seiring } \\
\text { dengan masalah-masalsh } \\
\text { kesehatan yane berkenbang } \\
\text { pada diri mereka }\end{array}$ \\
\hline $\begin{array}{l}\text { Kebutuhan } \\
\text { Tempat Tinezal }\end{array}$ & $\begin{array}{l}\text { Kominitas pensilunan, } \\
\text { Komunitas orang dewasa }\end{array}$ & $\begin{array}{l}\text { Perawatan untuk sekumpula } \\
\text { orane, pusat perawatan } \\
\text { berkelanjutan, perawatan di } \\
\text { area kediaman }\end{array}$ & $\begin{array}{l}\text { Pumah perawatan perawatan } \\
\text { residen, perswstan pribads }\end{array}$ \\
\hline
\end{tabular}

Sumber: Konsep Home pada Panti Sosial Tresna Werdha, 2009

Penuaan mempengaruhi mobilitas, pencapaian, penglihatan, dan sensisitivitas terhadap suhu (Dermartoto, 2006). Terlihat jelas Lansia mengalami kondisi semakin menurun sesuai usia, disertai dengan kemunduran fungsi pada sistem tubuh sehingga secara otomatis memperngaruhi psikologis, kondisi mental, keterasingan post-power syndrome, dan tentunya termasuk masalah penyakit.

WHO mengatakan terdapat enam faktor yang mempengaruhi proses penuaan, yaitu faktor sosial, ekonomi, perilaku, pribadi, layanan sosial dan kesehatan dan lingkungan fisik. Manusia dapat mencapai usia tua sebagai individu yang aktif atau memiliki kelemahan tingkat lanjut yang membahayakan kemampuan fungsional kita. Ada empat indikator yang dapat membuat lansia tetap aktif, yaitu kesehatan, edukasi dan pembelajaran lanjut, partisipasi sosial, dan keamanan.

Kesejahteraan lansia dapat dipenuhi melalui pemenuhan kebutuhan lansia, baik dalam segi aktivitas maupun kebutuhan ruang. Menurut teori Hierarki Kebutuhan Maslow (1943), kebutuhan manusia meliputi: (1) Kebutuhan fisik; (2) Kebutuhan rasa aman; (3) Kebutuhan sosial; (4) Kebutuhan harga diri; (5) Kebutuhan Aktualisasi diri. Sistem yang terbentuk dalam komunitas didasari oleh perhatian akan kebutuhan dasar manusia agar menghasilkan output yang sesuai dengan kebutuhan lansia.

\section{Bangunan untuk Lansia}

Bangunan harus dirancang sedemikian rupa agar terasa aman dan nyaman bagi lansia. James Lovelock, pencetus hipotesa GAIA, mengatakan bahwa semua komponen yang ada di bumi akan saling menyatu 
untuk membentuk sebuah interaksi yang akan menjaga stabilitas dan keseimbangan keadaan bumi. Hipotesa Gaia memandang bahwa bumi adalah sebuah organisme tunggal yang memiliki kehidupan. terdapat 3 elemen penting dalam hipotesa Gaia yang perlu diperhatikan untuk mencapai sebuah desain arsitektur yang baik bagi kehidupan, yaitu kesehatan jasmani, jiwa dan alam.

Ruang merupakan fasilitas berjalannya aktivitas manusia, dimana dalam melakukannya harus memberikan kenyamanan. Ketika berbicara mengenai ruang, manusia cenderung merespon atau berpersepsi. Menurut Itellson \& Prohansky (1970), persepsi lingkungan merupakan proses yang melibatkan komponen kognitf (berpikir), afektif (emosional) interpretative, dan evaluative yang berhubungan dengan panca indra.

Studi dari housing city of Westminster and the Westminster Municipal Code mengidentifikasikan 4 tipe jenis senior housing diantaranya Independent Living, Congregate Care, Assisted Living dan Skilled Nursing Facilities. Kebutuhan servis pada tiap-tiap jenis bangunan berbeda menyesuaikan kategori lansia dan jenis kehidupan lansia, seperti yang dapat dilihat dalam tabel di bawah.

Tabel 2. Living Solution and Services

\begin{tabular}{|c|c|c|c|c|c|}
\hline & & & & & \\
\hline & Lving at hoene & Senaor liviag & Secrate lovang & Nursang bome & Specialared cane \\
\hline Hoene senvices (HS) & YES & YES & YES & & \\
\hline Meals & Home Service & Sometumevits & Howe Service & YES & YES \\
\hline Clesning & Home Service & Sometimes/HS & Heene Service & YES & YES \\
\hline Access to nurve & Houne Senvice & SoanetimeuliS & Hoene Service & YES & YES \\
\hline Common ares & & Soenetimes & YES & YES & YES \\
\hline Activities & & Somitimn & YES & YES & \\
\hline Age & All & 55.75 , & $70-75+$ & All & All \\
\hline
\end{tabular}

Sumber: Edström, Annika \& Gustafsson, Madelene. 2011. Elderly Living in Sweden, Present solutions and future trends. Stockholm. Hans Lind

Menurut Senior Housing Design Guidelines (2009), terdapat 4 kategori untuk mendesain bangunan tinggal untuk lansia yaitu: (1) Site Design; (2) Architectural Design; (3) Landscape design; (4) Sustainable design. Bangunan di desain dengan mempertimbangkan ke empat aspek secara menyeluruh agar kenyamanan, keamanan, dan kemudahan bagi lansia terpenuhi.

\section{Desain Biofilik}

Desain biophilik adalah desain yang berlandaskan pada aspek biophilia yang bertujuan untuk menghasilkan suatu ruang yang dapat berpartisipasi dalam peningkatan kesejahteraan hidup manusia secara fisik dan mental dengan membina hubungan antara manusia dan alam. Di dalam buku 14 patterns of biophilic (2014), desain biofilik memiliki prinsip dalam penerapannya. Penerapan desain biofilik secara umum dapat memberi manfaat dalam mengurangi stres, kinerja kognitif, dan berdampak positif pada emosi. Keseluruhan prinsip tersebut dikelompokkan dalam tiga kelompok utama dengan 14 pola sebagai berikut.

\section{a. Nature in the space}

1. Visual connection with nature (hubungan dengan alam secara visual)

2. non-visual connection with nature (hubungan nonvisual dengan alam)

3. non-ryhthmic sensory stimuli (stimulus sensor tidak berirama)

4. Thermal \& airflow variabillty (variasi perubahan panas \& udara)

5. Presence of water (kehadiran air)

6. Dynamic \& diffuce light (cahaya dinamis dan menyebar)

7. Connection with natural systems (hubungan dengan sistem alami)

b. Natural Analogues Patterns

8. Biomorphic forms \& patterns (bentuk dan pola biomorfik)

9. Material connection with nature (hubungan bahan dengan alam) 
10. Complexity \& order (kompleksitas dan keteraturan)

c. Nature of The Space Patterns

11. Prospect and Refuge (prospek dan tempat perlindungan)

12. Mobility and Wayfinding (mobilitas dan jalan)

13. Mystery (misteri)

14. Risk/peril (resiko/bahaya)

Dalam buku the practice of biophilic design, Dr. Stephen R. Kellert menjelaskan 3 jenis pengalaman alam yang merupakan kategori dasar dari kerangka biophilic design, antara lain: (1) Hubungan langsung dengan alam; pencahayaan, udara, ventilasi, air, tumbuhan, hewan, cuaca, pemandangan alam dan ekosistem alam. (2) Hubungan tidak langsung dengan alam; gambar alam, material alami, warna, bentuk, meniukan cahaya dan udara alami, memunculkan alam. (3) Pengalaman ruang; prospek dan perlindungan, kompleksitas yang terorganisir, ruang transisi.

\section{METODE}

Metode perancangan kualitatif direalisasikan ke dalam proyek bangunan melalui tahapan: (1) Investigasi masalah dan pemilihan lokasi tapak; (2) Pemrograman; (3) Strategi Perancangan; (4) Deskripsi Desain. Sedangkan, konsep yang digunakan dalam penyelesaian perancangan ini sendiri menggunakan melalui metode space and programming serta sustainable dan resilience, dengan uraian sebagai berikut:

\section{a. Space and Programming}

Tidak ada arsitektur tanpa adanya aktivitas/kejadian di dalam suatu ruang. Dalam hal ini adalah aktivitas lansia yang terbatas. Proses berpikir kreatif Tschumi menjadi dasar dalam membentuk massa dengan menghadirkan Ide atau konsep, pembuatan program, sirkulasi, hingga penyusunan bentuk.

\section{b. Sustainable \& resilience}

Resilience mengaju pada proses adaptasi, menghadapi kerusakan, ancaman, tragedi, maupun trauma. Pada lansia sendiri dimaksudkan sebgai proses untuk bangkit dari presepsi lansia yang terpuruk karena minimnya kegiatan yang dapat dilakukan serta beketergantungan pada orang lain. resilience juga tidak terlepas dari pendekatan sustainable. Proyek ini di desain dengan menerapkan sistem green building pada bangunan untuk mendukung keberlanjutan lingkungan.

\section{DISKUSI DAN HASIL}

\section{Pemilihan Lokasi}

Lokasi yang terpilih melalui pertimbangan variabel seperti tingkat ekonomi dan kepadatan penduduk, untuk menentukan target pengguna menengah keatas. IPKM menunjukan bahwa penduduk di Jakarta Utara memiliki tingkat kesehatan yang cukup baik dengan mengalami peningkatan pada tahun 2018, serta pendapatan penduduk Jakarta Utara yang berada di tingkat menengah.

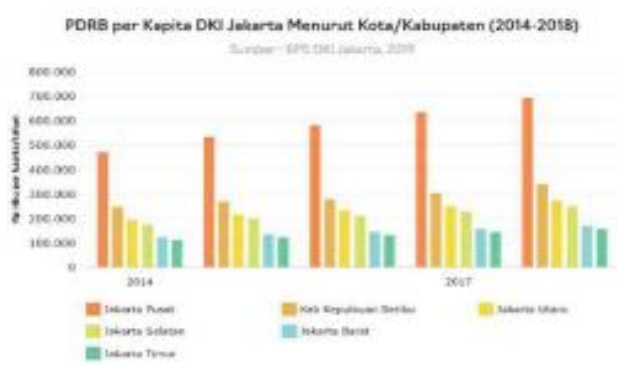

Gambar 3. PDRB per Kapita DKI Jakarta Sumber: BPS, 2019

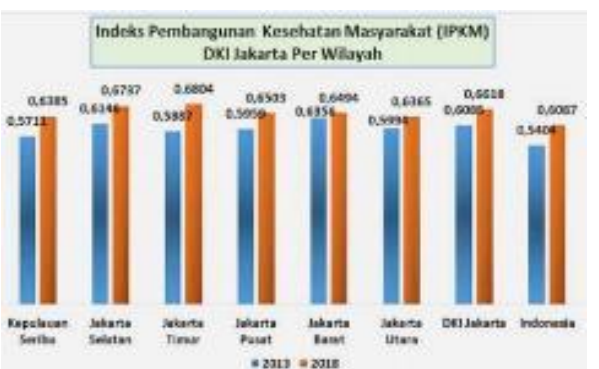

Gambar 4. IPKM DKI Jakarta per wilayah Sumber: BPS, 2018 
Tapak terpilih di kawasan Tanjung Priok Kelurahan Papanggo, terletak di area permukiman yang menyebabkan lansia masih dapat berhubungan dengan keluarganya. Luas tapak sebesar $7.100 \mathrm{~m} 2$ dengan zona perumahan vertikal. Jalan yang dilalui merupakan tipe jalan permukiman. RTH yang ada di kawasan masih sangat minim dan okupansi lahan cukup padat, sehingga solusi open space dan grenness dihadirkan dalam rancangan.

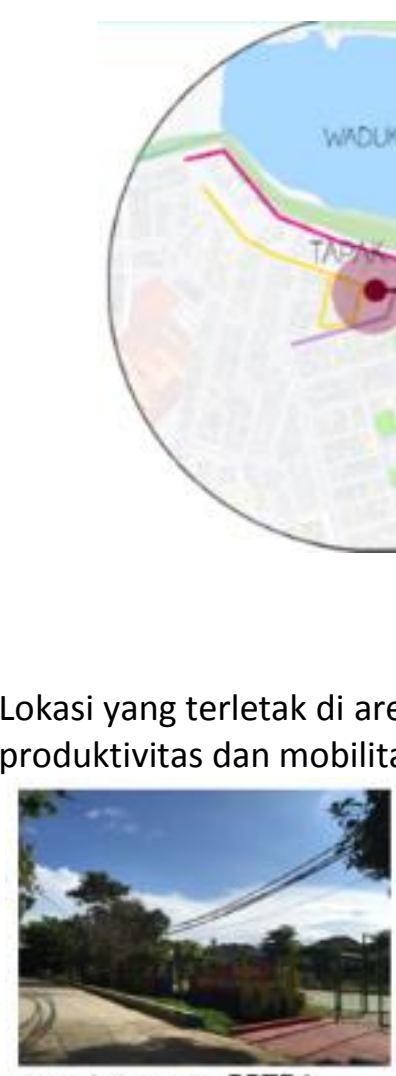

Samping tapak - RPTRA

Ping topok - RPTRA

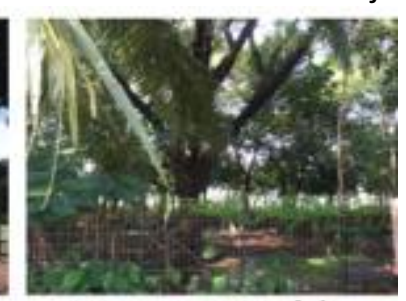

depan tapak - Waduk

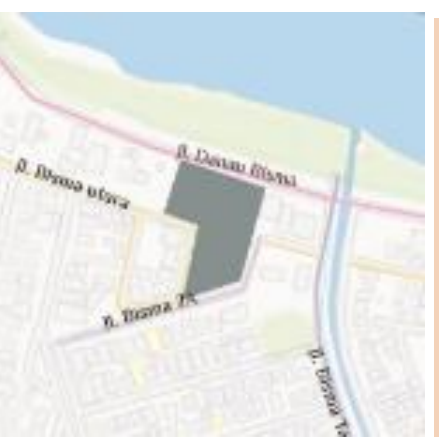

Gambar 5. Lokasi Tapak Terpilih

Sumber: Dokumentasi Pribadi, 2021
Tapok terletak di I. Danau Bisma, RT.5/RW:10, Papangso, 1], Priok, Kota Ikt tiara, Dacrah Khusus Itouvota lakarta 14340

Dereco 7ona Perımahan Vertikal dion peociseda xangunan; $\mathrm{KTB} 35$ KIB 2

$\mathrm{KB} \&$

KDH 30 KTB 55

Lokasi yang terletak di area permukiman akan mendorong suatu konsep berhuni baru. Dengan begitu produktivitas dan mobilitas lansia akan terus berjalan melalui fasilitas pendukung yang ada di proyek.

\section{Gambar 6. Lokasi Existing}

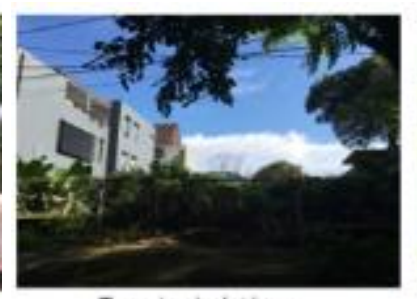

Tapak eksisting

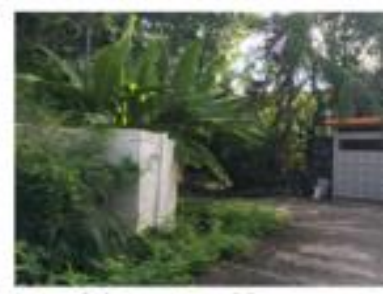

jalan permukiman

Sumber: Dokumentasi Pribadi, 2021

\section{Pemrograman}

Kategori pengguna proyek adalah komunitas independent living atau orang dewasa yang lebih tua, yang berusia 55 tahun ke atas. Program di dapat dari analisis potensi kebutuhan pengguna penduduk lansia, khususnya di Jakarta, yang mencakup aspek seperti demografi, tingkat kesehatan lansia, keseharian lansia, dan status tinggal bersama lansia. Dari ke empat aspek ini didapat usulan program yang dapat dimasukan ke proyek, yaitu: (1) Co-Housing Khusus Lansia; (2) Komunitas Lansia; (3) Area Komunal; (4) Market; (5) Klinik; (6) Servis.

Dari usulan program tersebut, didampingi oleh perhitungan luasan yang didasari oleh peraturan bangunan, didapat 2 program utama yaitu komunitas lansia dan hunian bersama khusus lansia. Kedua program ini saling terkait untuk mewadahi aktivitas lansia baik, baik yang merupakan penghuni maupun pengunjung harian (daycare). persentase program dalam proyek dan skema program ruang dapat dilihat di gambar 7 dan gambar 8 . 


KOMUNITAS
SENIOR CO-
HOUSING
$\begin{aligned} & \text { CARE CENIER } \\ & \text { (KLINIK + R. } \\ & \text { MEDITASI) } \\ & \text { KOMERSIL }\end{aligned}$
SERVIS
RTH

Gambar 7. Presentase program Sumber: Dokumentasi Pribadi, 2021

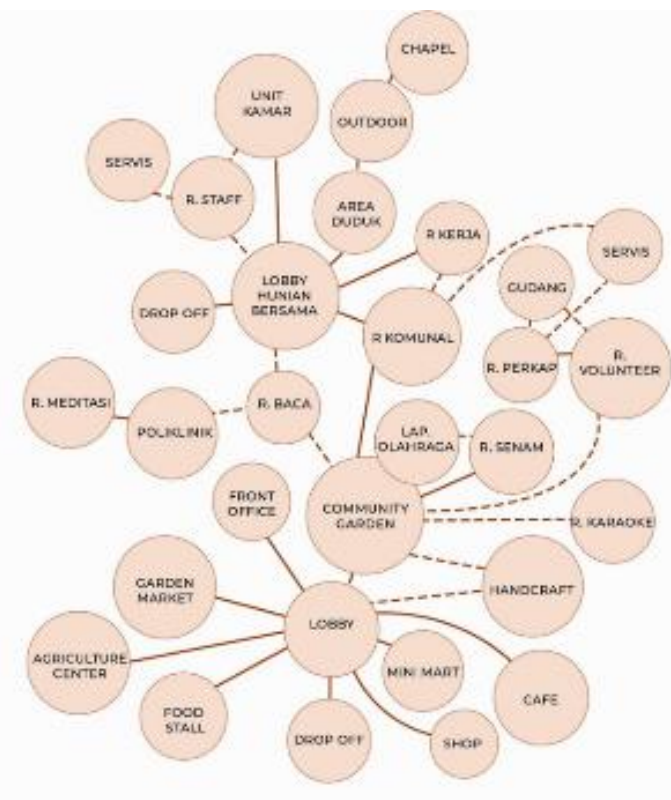

Gambar 8. Skema Program Ruang Sumber: Dokumentasi Pribadi, 2021

Program hunian terdiri dari 2 tipe, yaitu unit untuk lansia single dan lansia couple. Jumlah unit didapat dari studi beberapa komunitas lansia/ panti werdha yang terdapat di Jakarta dan sekitarnya. Kamar lansia single terdiri dari 34 unit dengan ukuran $20 \mathrm{~m}^{2}$. Kamar couple berjumlah 20 kamar dengan ukuran $48 \mathrm{~m}^{2}$. Di tiap unit terdapat balkon untuk pencahayaan alami. Total luasan hunian adalah sebesar $1640 \mathrm{~m}^{2}$ dengan total unit 54 unit.

Program pendukung terdiri dari area komunitas, klinik, agriculture center, dan pendukung lainnya dengan total luas sebesar $3750 \mathrm{~m}^{2}$. Total program ruang dalam proyek adalah sebesar $5390 \mathrm{~m}^{2}$.

\section{Strategi Perancangan}

Pendekatan ekologi pada lansia mengarahkan pada hubungan antara lingkungan dan keberlanjutan manusia, serta membentuk sebuah sistem yang dapat mewadahi aktivitas lansia. Ketiga unsur (manusia, alam, dan program) dimasukan ke dalam perancangan melalui proses pembentukan massa yang bertolak dari keadaan lingkungan sekitar.

Pembentukan Massa. Proses pembentukan massa dilakukan dengan menentukan bentuk dasar massa, pembagian zoning, menentukan ketinggian bangunan, membentuk atap yg disesuaikan dengan arah angin (angin kemarau di timur dan angin hujan di sebelah barat), dan penggunaan material sustainable.
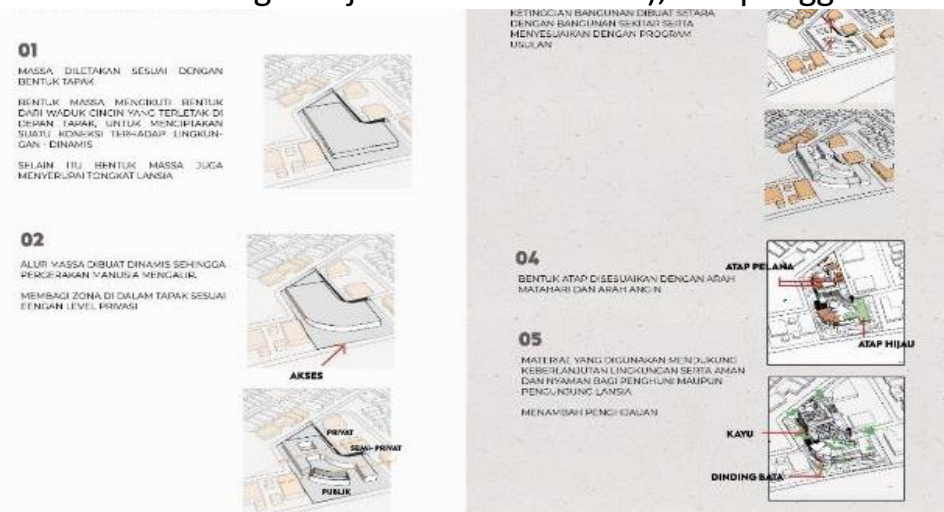

Gambar 9. Proses Gubahan Massa

Sumber: Dokumentasi Pribadi, 2021 
Material ramah lingkungan. Eksterior didominasi oleh penggunaan green wall yang berfungsi untuk meredam kebisingan, meminimalisir efek panas matahari serta penangkap air hujan. Terdapat atrium berupa penghijauan di outdoor yang menghubungkan antar program aktivitas. Atrium hijau memastikan bahwa penghuni atau pengunjung mengakses cahaya, penghijauan, dan udara yang baik.

Sirkulasi yang dinamis, ditujukan agar lansia dapat dengan mudah mengakses ruang-ruang yang ada. dapat menikmati beraneka ragam aktivitas mulai dari memasak, menyalurkan hobi hingga bercocok tanam.

Pendekatan Biofilik. Diterapkan melalui penggunaan material maupun konsep desain bangunan. hal ini untuk menciptakan suasanan aman dan nyaman di dalam komunitas dan berdampak positif pada kesehatan mental lansia.

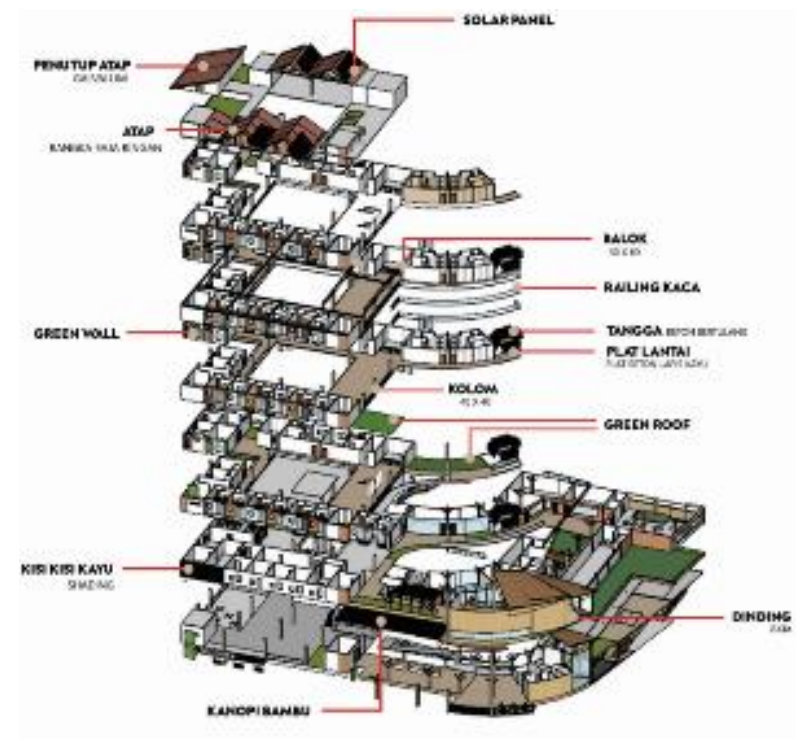

Gambar 10. Penggunaan Material pada Struktur Sumber: Dokumentasi Pribadi,2021

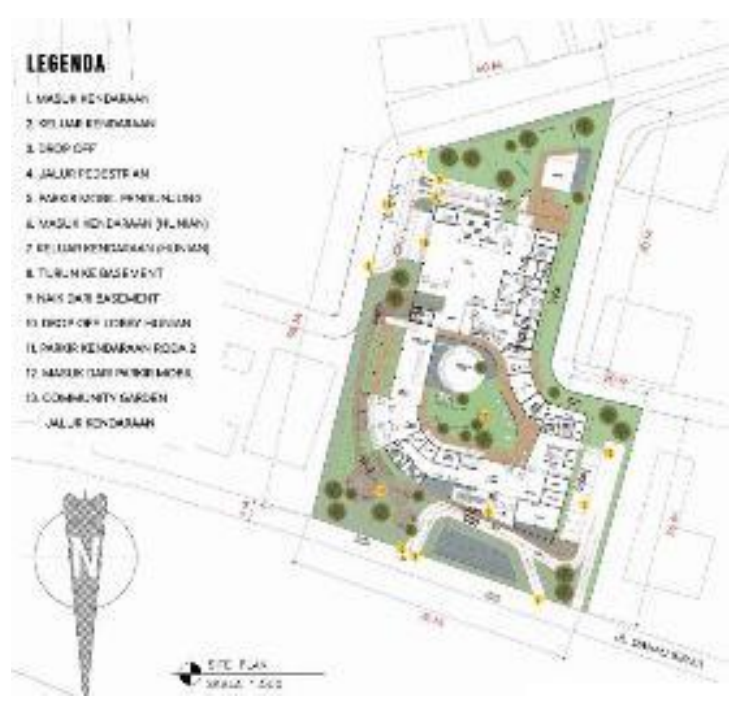

Gambar 11. Sirkulasi Dinamis Sumber: Dokumentasi Pribadi, 2021

\section{Deskripsi Desain}

\section{Penerapan konsep desain biofilik}

Komunitas dan hunian lansia ini disain dengan konsep desain biofilik, yang memiliki tujuan untuk menghasilkan suatu ruang yang dapat berpartisipasi dalam peningkatan kesejahteraan hidup manusia secara fisik dan mental. Konsep desain yang terhubung dengan alam dapat membantu lansia secara psikologis untuk merasa tenang dan nyaman, baik dalam bersosialisasi maupun berhuni sendiri atau bersama pasangan. Penerapan ketiga prinsip utama biofilik di dalam proyek terlihat melalui:

\section{a. Nature in the space}

Menghadirkan hubungan secara visual menuju pemandangan alam di atrium tengah, dengan membentuk suatu pengalaman di alam melalui taman bersama. Gerakan angin dapat dirasakan oleh manusia dikarenakan dinding yang tidak masif. Kehadiran air di atrium tengah menambah pengalaman individu dengan melihat dan mendengar. Intensitas cahaya alami dinamis dan menyebar menghadirkan kondisi perubahan waktu dan suasana dari pagi hingga malam. Dinding hijau meminimalisir udara panas (thermal) dan menghadirkan visual alam. 


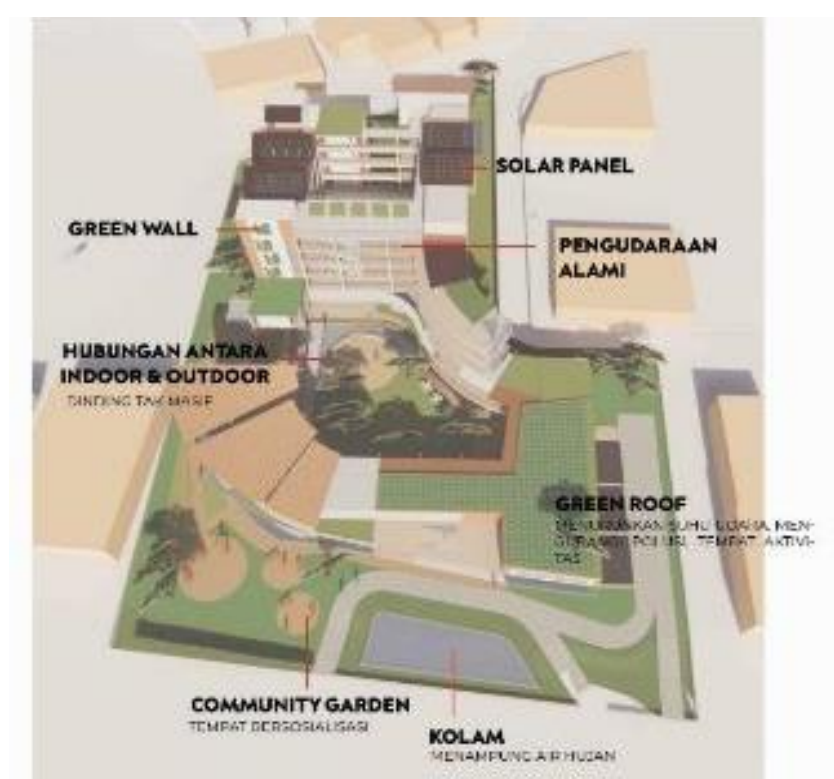

Gambar 12. Penerapan desain biofilik dalam bangunan

Sumber: Dokumentasi Pribadi, 2021

\section{b. Nature Analogues Patterns}

Kolom dibentuk menyerupai pohon untuk menghadirkan kesan cinta alam. Material alam dihadirkan dalam tekstur kayu dalam dinding dan lantai. Menggunakan berbagai material alami yang ramah lingkungan seperti kayu, dinding bata, atap ekspose, dan atap hijau.

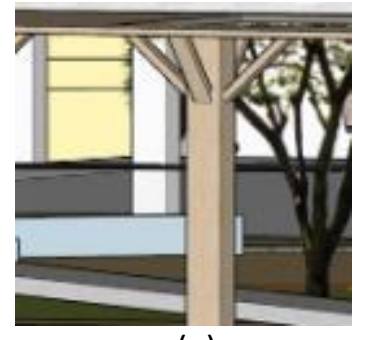

(a)

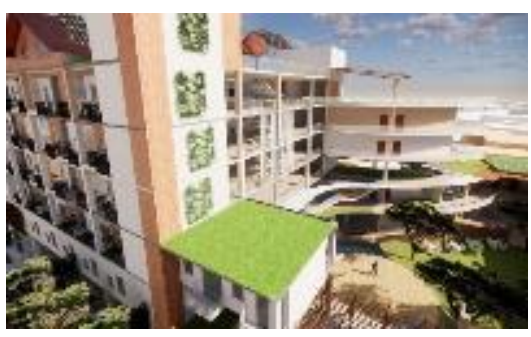

(b)

Gambar 13. (a) Desain kolom. (b) Material alami

Sumber: Dokumentasi Pribadi,2021

\section{c. Nature of The Space Patterns}

Mendesain ruang dengan pandangan yang terbuka dengan penyediaan atrium hijau di community garden dan dinding setinggi $90 \mathrm{~cm}$. Memberikan rasa aman dan terlindungi pada penggunaan melalui akses yang terpisah antara penghuni dan pengunjung. Menciptakan suasana yang nyaman melalui pola pergerakan yang dinamis serta penggunaan ramp untuk pergerakan lansia yang terbatas. 


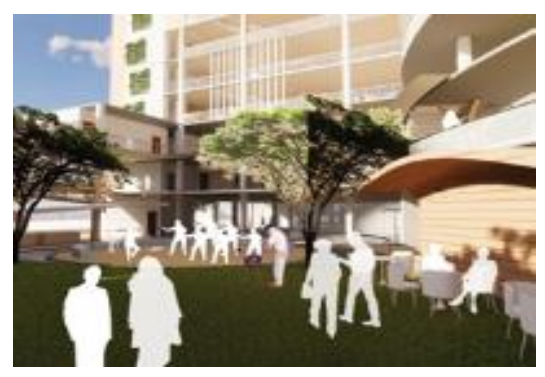

(a)

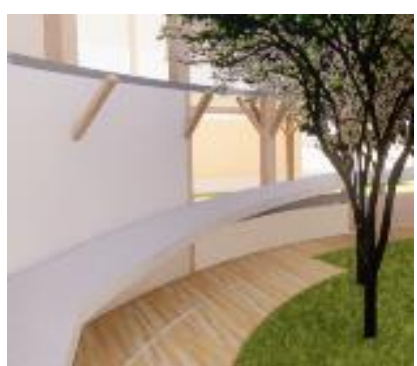

(b)

Gambar 14. (a) Community garden. (b) Ramp menuju It 2. Sumber: Dokumentasi Pribadi

Selain itu, pengalaman dalam komunitas lansia berbasis desain biofilik dapat dilihat dari: (1) Hubungan langsung ke alam dengan menghadirkan hubungan langsung ke cahaya, udara, air, dan tumbuhan. Pengalaman dengan pemandagan yang alami melalui interaksi langsung ke alam, baik di atrium hijau maupun di agriculture center; (2) Hubungan tidak langsung dengan menggunakan material alami seperti kayu dan atap hijau, serta penggunaan warna yang alami seperti coklat. Bentuk yang alaml dimunculkan dalam desain kolom yang menyerupai ranting pohon dan Geometri bentuk berliku pada pembentukan massa; (3) Pengalaman ruang didapat antara lain dari strategi desain yang memberikan pemandangan terhadap area luar dan antar ruang dalam sehingga manusia dapat merasa aman dan terlindungi. Selain itu ruang transisis yang menghubungkan antara ruang dalam dan luar.

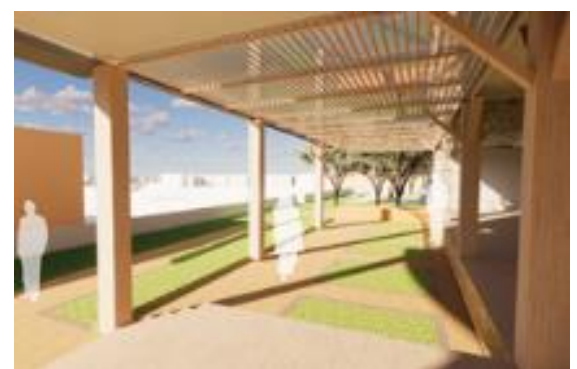

(a)

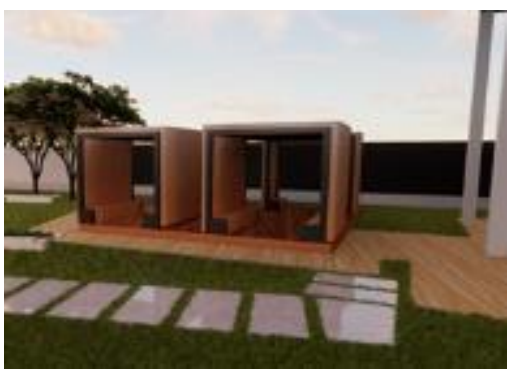

(b)

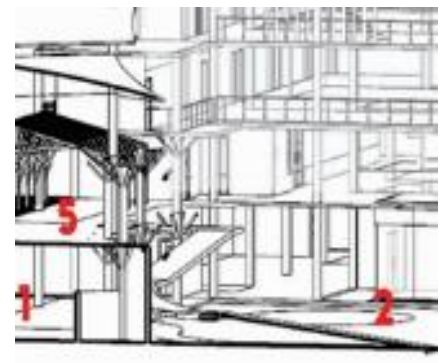

(c)

Gambar 15. (a) Agriculture Center. (b) Material dan warna alami. (c) transisi indoor/outdoor Sumber: Dokumentasi Pribadi, 2021

\section{Hasil Desain Rancangan}

Fasad bangunan menggunakan material bata yang dilapisi oleh kayu atau green wall. Pada bagian penutup atap menggunakan dua tipe yaitu 1) atap hijau yang berfungsi untuk menurunkan suhu udara dan menyerap air hujan; 2 ) atap rangka baja ringan yang memiliki kemiringan kurang lebih lima belas derajat agar air hujan dapat dialirkan dan cahaya matahari tidak langsung masuk ke ruangan. 


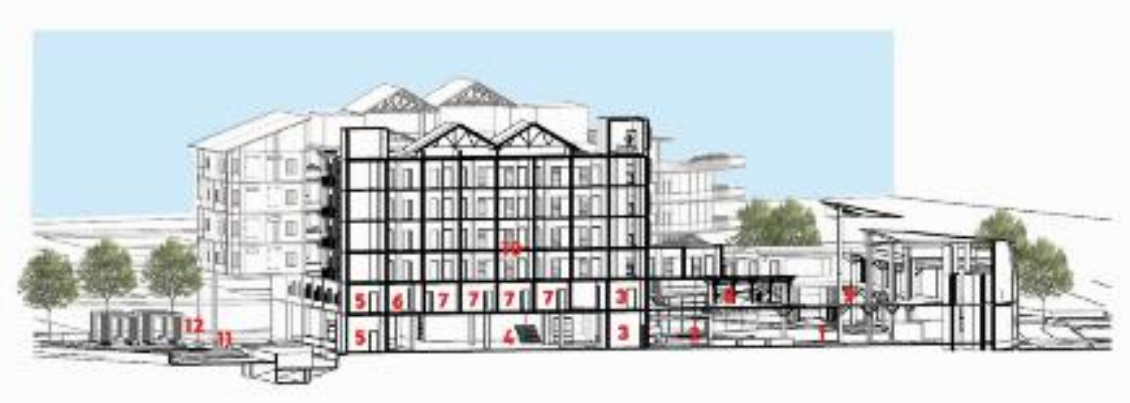

1. FRESH MARKET

2. AGRICULTURE CENTRE

3. LFT SERVICE

4. LOBEY

5. TANGGA DARURAT

D. R. REDTASE

T. KLIHIK

5. TAMAN

2. AOEAMAKAN

10. HUNIAN TIFE 1

11. OUTOOOR

12. CHAPEL

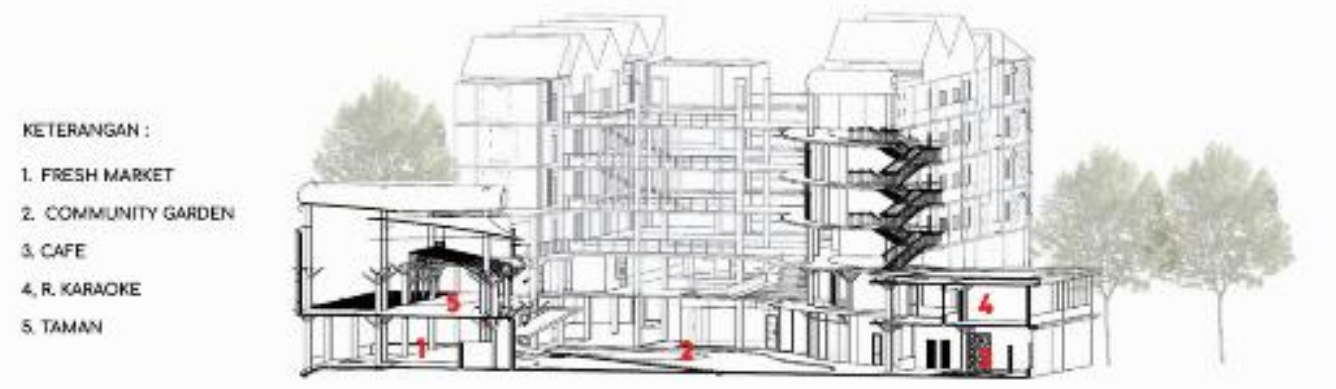

Gambar 16. Sequence pergerakan pada proyek

Sumber: Dokumentasi Pribadi, 2021

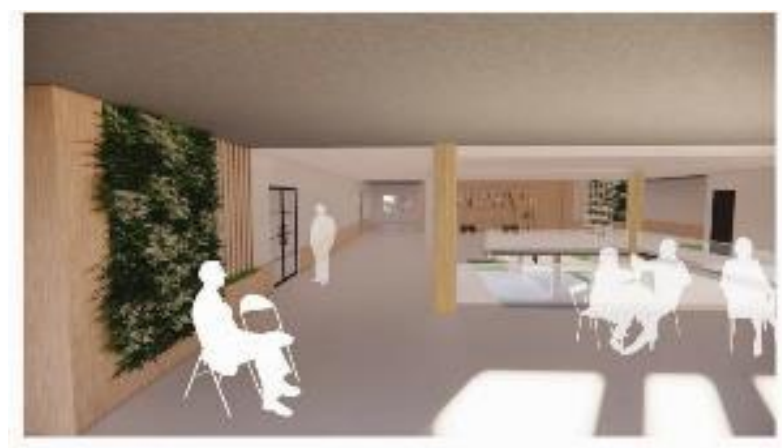

Gambar 17. Klinik

Sumber: Dokumentasi Pribadi, 2021
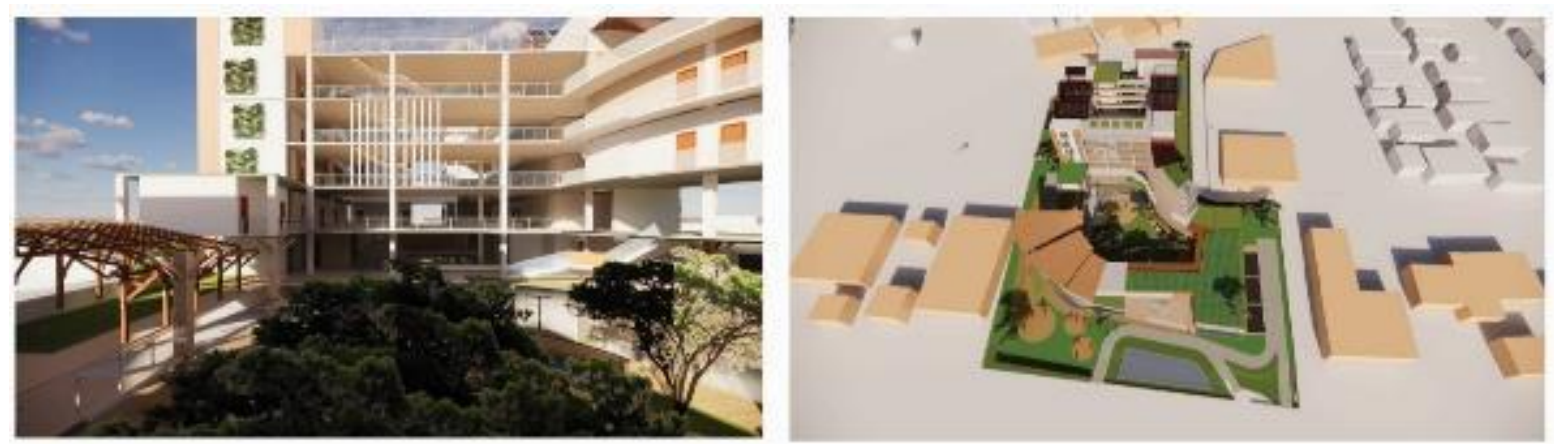

Gambar 18. (a) Tampak dari dalam (b) Tampak dari atas

Sumber: Dokumentasi Pribadi, 2021 

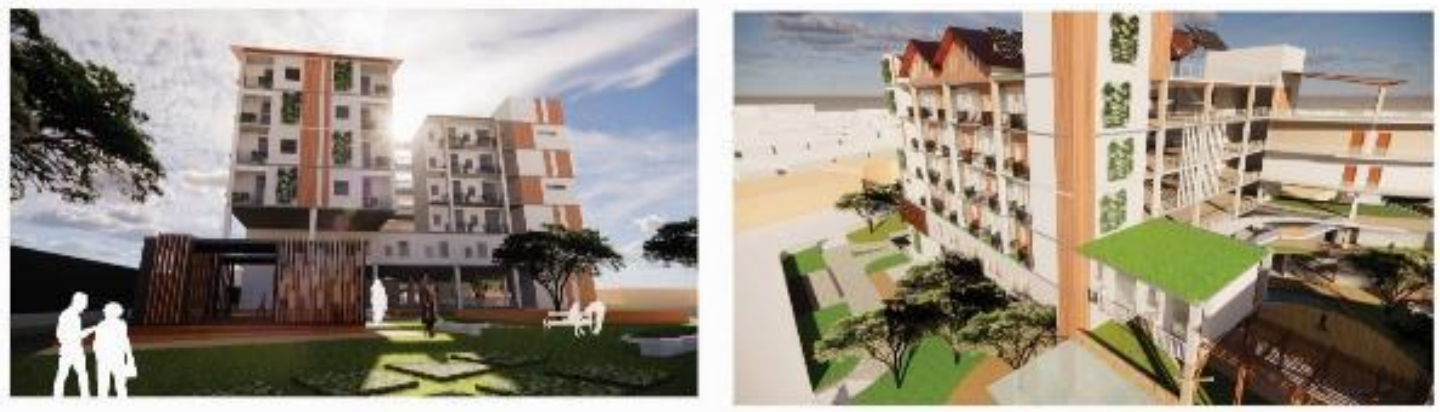

Gambar 19. (a) Tampak Belakang. (b) Hunian.

Sumber: Dokumentasi Pribadi, 2021

\section{KESIMPULAN DAN SARAN}

\section{Kesimpulan}

Masalah penuaan merupakan salah satu proses dari kehidupan manusia yang tidak dapat dihindari. Proyek komunitas lansia dapat dikatakan sebagai salah satu wadah untuk mendukung kebutuhan lansia agar tetap aktif dan produktif. Lokasi yang terletak di Jakarta Utara diyakini dapat memenuhi perkembangan lansia di generasi mendatang sesuai dengan target pengguna. Dengan menghadirkan sebuah konsep keberlanjutan di dalam bangunan melalui program yang ada, lansia diharapkan dapat beraktivitas dengan suasana yang nyaman melalui pola pergerakan yang dinamis untuk mendukung pergerakan lansia yang terbatas. Penerapan desain biofilik dalam perancangan komunitas lansia dapat menghasilkan suatu ruang yang dapat berpartisipasi dalam peningkatan kesejahteraan hidup manusia secara fisik dan mental, dengan membina hubungan antara manusia dan alam.

\section{Saran}

Dalam mendesain komunitas lansia harus memperhatikan mobilitas manusia yang menua dan lebih terbatas. Akan lebih baik jika dalam merancang sebuah komunitas lansia menemukan data yang lebih detail mengenai sasaran penghuni dan program yang diusulkan. Penerapan desain biofilik dalam perancangan komunitas lansia diharapkan dapat menjadi referensi dalam mendesain komunitas yang berbasis healing dan well-being.

\section{REFERENSI}

Browning, W., Ryan, C., \& Clancy, J. (2014). Fourteen Pattern of Biophilic Desicn. New York: Terrapin Bright Green, LLC.

Jane, S., \& Thoday, P. (1996). Landscape Design for Elderly and Disabled People. Michigan: Garden Art Press.

Chung S. Residential status and depression among Korean elderly people: a comparison between residents of nursing home and those based in the community. Health Soc Care Community. 2008 Jul; 16(4): 370-7

Maryam, R. Siti dkk. (2011). Mengenal Usia Lanjut dan perawatannya. Jakarta : Salemba Medika.

Senior Housing Design Guidelines. (2009). City of Westmister

Fatimah. (2010). Merawat Manusia Lanjut Usia Suatu Pendekatan Proses Keperawatan Genotik. Jakarta: Trans Info Media

Setyoadi, Noerhamdani, Ermawati F.. Perbedaan Tingkat Kualitas Hidup pada Lansia Wanita di Komunitas dan Panti [internet]. 2010. [2012 September 19]. Available: http://unbra.ac.id.

S.Kellert and E.Calabrese. (2015). The Practice of Biophilic Design.

Copper, C., Francis, C. (1998). People Places second edition. USA: International Thomsom Publishing

Proshansky, H. M., Ittelson, W. H., \& Rivlin, L. G. (1970). Environmental Psychology: Man and His Physical Setting. New York: Holt, Rinehart and Winston

https://statistik.jakarta.go.id/statisik-penduduk-lanjut-usia-di-dki-jakarta-tahun-2019/

http://jkn.jamsosindonesia.com/ 